\title{
Anode and Cathode Arc Root Movement During Contact Opening at High Current
}

\author{
John W. McBride and Peter A. Jeffery
}

\begin{abstract}
This paper presents experimental research into the behavior of short circuit break arcs ignited between opening contacts. The investigation is applied to arc chamber geometries commonly used in miniature circuit breakers (MCB). The movement of the anode and cathode roots are individually plotted from optical data, allowing the relative motion to be compared. The effect of a range of MCB configurations on the arc root motion has been investigated. The experiment was configured so that the fixed contact was always the cathode. The results show that the two arc roots do not move away from the contact region simultaneously. Often the cathode root moved off the fixed contact and away from the contact region before the anode root commutated from the moving contact. The delay in anode root commutation leads to a delayed cathode root movement. These events are explained in terms of arc root emission processes.
\end{abstract}

Index Terms-Arc motion, contact motion, current limiters.

\section{INTRODUCTION}

$\mathbf{T}$ HIS paper presents experimental results from a test system design to recreate the current limiting operation of a miniature circuit breaker (MCB). Miniature circuit breakers are widely used in domestic, commercial and light industrial installations. The devices are usually used where the supply voltage exceeds $200 \mathrm{~V}$ ac and are used to protect circuits rated up to $100 \mathrm{~A}$ from overload and short circuit faults $\left(10^{3}-10^{4}\right.$ A prospective). During a short circuit fault an electric arc is drawn between opening contacts. The current through the conductors of the MCB generates a magnetic field in the arc chamber, which acts to force the arc away from the contact region along arc runners and into an arc stack. The arc is then split into a number of series arcs which results in a high voltage across the circuit breaker. The high voltage counteracts the supply voltage and limits the peak fault current. The energy released by the fault is reduced and damage to both the circuit and the circuit breaker is minimized.

This paper follows on from a previously published paper [1], where the test system and arc imaging system used here were described in detail. A method for the detection of arc root position was presented, and has been developed here to allow for the evaluation of both anode and cathode arc roots. Results are presented for a range of arc chamber geometries

Manuscript received December 1, 1998; revised January 12, 1999. This paper was recommended for publication by Guest Editor M. Braunovic upon evaluation of the reviewers' comments. This paper was presented at the $42 \mathrm{nd}$ IEEE Holm Conference on Electrical Contacts, Chicago, IL, September 16-20, 1996.

The authors are with the Departments of Mechanical and Electrical Engineering, Electro-Mechanical Research Group, University of Southampton S017 1BJ, U.K.

Publisher Item Identifier S 1521-3331(99)03283-3. and test conditions. The importance of anode root mobility in opening contacts is identified and related to the emission process occurring at the cathode.

\section{A. Cathode Root Emission Mechanisms}

The emission mechanism at a cathode root will vary over the duration of an arc and will affect the arc motion. The cathode root is the source of electrons for the current through the arc column, and is generally considered to dominate the movement of the arc column. There are two main emission mechanisms, thermionic and field emission.

\section{B. Thermionic Emission}

Thermionic emission occurs when a refractory electrode material is heated to a sufficiently high temperature. Thermionic cathode arc roots on refractory materials have been observed to be stable and stationary with current densities of 10-100 $\mathrm{A} / \mathrm{mm}^{2}$.

The contact and arc runner materials used in MCB's are usually alloys of low melting point metals such as copper and silver, known as cold-cathode materials. Arc roots on cold cathode materials have been observed to be highly unstable and mobile with high current densities at the root of $10^{4}-10^{5} \mathrm{~A} / \mathrm{mm}^{2}$. Thermionic emission theory cannot explain the current densities measured at the cathode of arcs on cold cathode metals, as the melting point is lower than the temperatures required for significant thermionic emission. A number of different nonthermionic emission mechanisms have been proposed [2]. It is likely that a number of these mechanisms occur simultaneously within the cathode root, with one mechanism dominating at any particular time [3]. Other types of circuit breaker can use combinations of $\mathrm{AgW}$ and $\mathrm{Ag} / \mathrm{C}$ contact materials where thermionic emission is thought to be an additional effect due to the presence of refractory Tungsten and Carbon.

\section{Field Emission}

Electrons can be extracted from a cathode material by strong electric fields. Although the average field strength between the arc electrodes in an MCB is not high enough to cause field emission it is thought that there may be a high field strength local to the cathode surface. Two potential causes of this high strength electric field were reviewed by Sloot and Bosch [4]. The high field required may be produced by the space charge of positive ions collecting in the cathode fall region. The positive ions are produced by collisions between electrons and atoms 


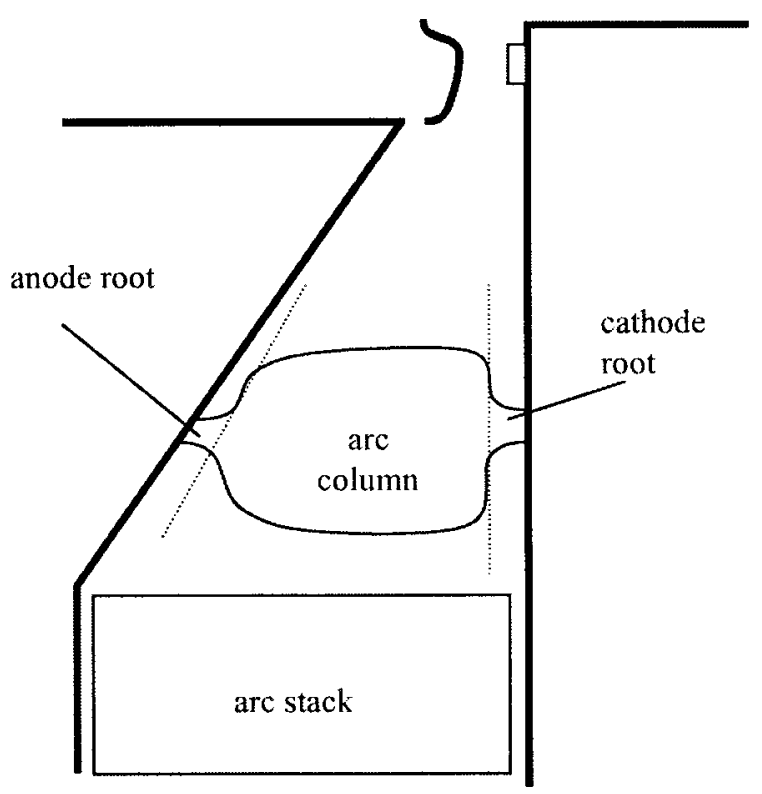

Fig. 1. Schematic diagram of a $1 \mathrm{kA}$ arc in arc chamber geometry A. Based on data from optical fiber imaging system.

of metal vapor that have evaporated from the cathode. An arc sustained by this type of field emission is known as a metal vapor type arc. Alternatively, thin oxide layers on the surface of the electrode may trap positive ions resulting in a high electric field. An arc sustained by this type of emission is known as an oxide-layer type arc

\section{Arc Behavior Between Opening Contacts}

When an arc is ignited between separating contacts, the initial arc roots will be drawn on a molten metal surface. Metal vapor type field emission will dominate and the movement of the arc will be determined by the velocity of the temperature front of the molten region, the arc root will therefore be limited to low velocity movement [5]. In this investigation the current flowing though the contacts as the arc ignites is approximately $700 \mathrm{~A}$ and can rise to $2 \mathrm{kA}$ during arc movement. At the current densities quoted for a free burning arc in air [2] the arc is likely to be constrained by the sidewalls of an arc chamber. In Fig. 1, an arc of $1 \mathrm{kA}$ is draw in the arc chamber of a MCB, based on observed data from an imaging system. The figure shows one of the geometries used in this experimental study. The arc is ignited between the opening contacts at the top of the figure and is forced down through the arc chamber into the arc stack. The magnetic forces on the arc may result in the arc column being displaced sufficiently for a new site of electron emission to occur on a metal oxide layer away from the site of arc ignition. Once this site of electron emission on the oxide layer has become established the arc can move at high velocity. The velocity of the arc root is then governed by the charging characteristics of the oxide layer [4].

As techniques to record the arc behavior have improved more details of arc phenomena have emerged. Arc immobility at the ignition site, arc commutation, periods of reduced arc motion, and the arc running time (arc lengthening time) have all been identified as separate phenomena [1], [6], [7]. In

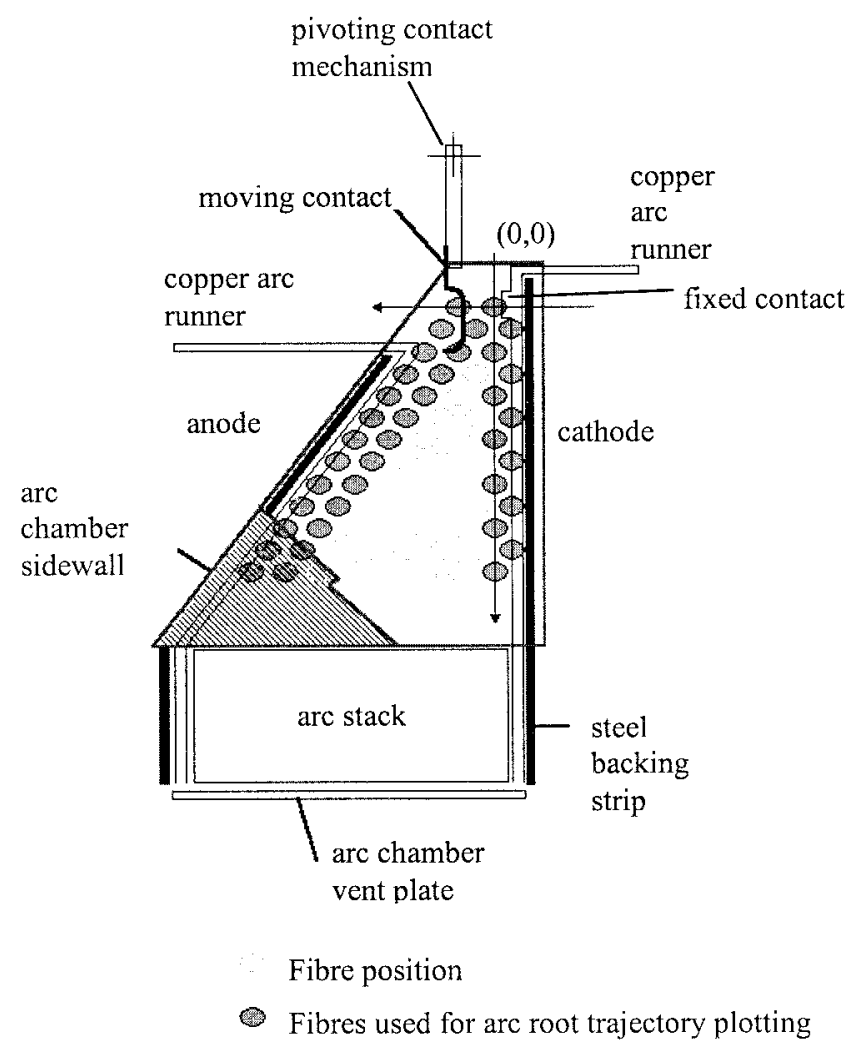

Fig. 2. Arc chamber geometry A, with optical fiber positions, and pivoting contact mechanism. $X$ and $Y$ directions are measured relative to the $(0,0)$ position.

most cases investigations have been conducted on parallel arc runners, without opening contacts. The investigation presented here makes use of an optical fiber imaging system with unique image processing methods to identify the details of the events which affect the arc motion as the high current arc is ignited between opening contacts. Two investigations are presented. The arc contact time investigation examines the effect of the contact configuration on the period of time that the cathode root remains on a fixed contact. In the arc behavior investigation, the movement of both the arc roots along the arc chamber is considered, for a range of contact and arc chamber configurations.

\section{EXPERIMENTAL Method}

\section{A. Test System}

A high speed arc imaging system (AIS) has been used to record optical data of arc motion at sample rates of 1 $\mathrm{MHz},[8]-[10]$. The short circuit tests were carried out in a flexible test apparatus (FTA) designed to simulate the current limiting operation of a MCB [1]. Figs. 2 and 3 show details of the arc chambers used to simulate MCB geometry (A) and (B), respectively. In geometry (A) the fixed contact is connected to a long straight runner, whereas in (B) the fixed contact runner diverges at the corner identified in Fig. 3. The circles over the arc chambers indicate the optical fiber positions. The contacts are opened with a solenoid mechanism, which operates independently of the fault current. Two contact 


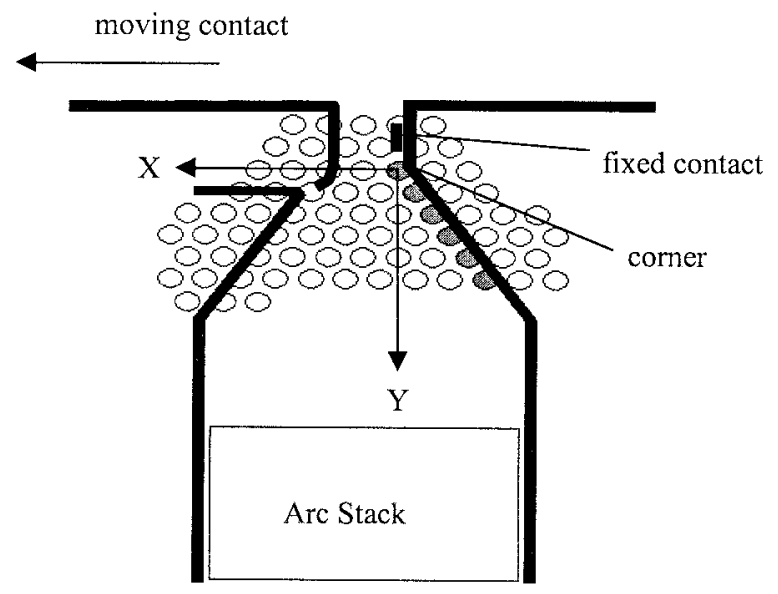

Fig. 3. Arc chamber geometry B, with optical fiber positions, and a linear moving contact. The $X$, and $Y$ directions are shown relative to the fixed contact corner.

TABLE I

Experimental Factors Which Have Been Held Constant

\begin{tabular}{l||l}
\hline \hline Factor & Constant Value \\
\hline \hline Capacitor charge voltage & $350 \mathrm{~V}$ \\
\hline Inductance & $224 \mu \mathrm{H}$ \\
\hline Capacitance & $47.4 \mathrm{mF}$ \\
\hline Final contact gap & $6 \mathrm{~mm}$ \\
\hline Contact mechanism and velocity & Pivoting mechanism $10 \mathrm{~m} / \mathrm{s}$, \\
\hline Moving contact & Lincar mechanism $3 \mathrm{~m} / \mathrm{s}$ \\
\hline Contact polarity & Silver plated copper \\
\hline Contact opening delay $\mathrm{t}_{\text {cod }}$ & Fixed contact negative \\
\hline Chamber depth & $500 \mu \mathrm{s}$ \\
\hline Chamber attitude & $6 \mathrm{~mm}$ \\
\hline Arc stack displacement & Horizontal \\
\hline \hline
\end{tabular}

mechanisms were used, a linear mechanism for tests with contact velocities of $3 \mathrm{~m} / \mathrm{s}$ and a pivoting mechanism for the higher velocities of $10 \mathrm{~m} / \mathrm{s}$. A prospective peak current of $3.5 \mathrm{kA}$ at a simulated frequency of $50 \mathrm{~Hz}$ was used for both investigations. The short circuit is simulated using a capacitive discharge system; circuit component values are defined in Table I. The opening of the contacts can be controlled and has been set in these experiments to $0.5 \pm 0.1 \mathrm{~ms}$ after the start of the short circuit current pulse.

Techniques have been developed that allow the trajectory of the two arc roots to be plotted separately from the AIS data, based on the method identified in [1]. The method has been extended to measure the time period that each arc root remains in the contact region, known as the cathode root contact time $\left(t_{c}^{-}\right)$and the anode root contact time $\left(t_{c}^{+}\right)$.

\section{B. Supply Polarity}

In a previous paper, [1] initial studies were undertaken on the arc root movement in the contact region of geometry (B), Fig. 3. Consideration was given to the influence of polarity on arc movement away from the fixed contact. It was shown that for geometry (B) the cathode root on the fixed contact provided the longest period of delay. In this study the polarity has been fixed so that the fixed contact is always the cathode.

\section{Experimental Conditions}

Two separate investigations are presented here. Table I gives the experimental constants for both investigations.

Experiment 1-Arc Contact Time Investigation: The main objectives were to investigate the effect of geometry and contact velocity in a controlled experiment before developing a more complex experimental methodology used in Experiment 2 . In the arc contact time investigation the arc root contact times were calculated for a range of contact and arc runner configurations. The experimental programme is given in Table II. All the trials were carried out at $3 \mathrm{~m} / \mathrm{s}$ opening velocity using the linear contact mechanism except Trial A6, which used the pivoting mechanism. Two arc chamber geometries were used with ceramic sidewalls: Geometry A with one diverging arc runner, Fig. 2, and Geometry B with two diverging arc runners, Fig. 3.

Experiment 2-Arc Behavior Investigation: In this experiment the objective was to investigate a wide range of arc chamber parameters having identified the ideal geometry for doing this from the two used in experiment 1 . For the arc behavior investigation the Taguchi method was used to plan a partial factorial experiment using a L9 orthogonal array and nine trials [11]. The Taguchi Method is used to design an efficient experiment that covers the maximum number of test factors with the minimum number of trials. In a Taguchi experiment the level of all but one experimental factor are varied between trials. Taguchi analysis can be carried out on the results to compensate for the reduced set of trials. The "average effects" of each factor can be deduced and any interactions between trials identified.

Arc Chamber Geometry A and the pivoting contact mechanism $(10 \mathrm{~m} / \mathrm{s})$ were used. The contact configuration, arc runner configuration, arc chamber materials and arc chamber venting were set to three levels, as shown in Table III. The experimental programme of nine trials is presented in Table IV. Each trial was replicated eight times. The "average effects" results of the Taguchi analysis have been presented previously [12]. Here the experimental data recorded during the Taguchi experiment is re-examined in a comparative analysis.

\section{RESULTS}

The results of Experiment 1 are shown in Fig. 4, for both the let through energy and the cathode root contact time $\left(t_{c}^{-}\right)$ for arc chambers, A and B, for the range of experimental conditions shown in Table III.

The results of Experiment 2 are shown in Figs. 5(a) and (b), for the Taguchi based experimental method, and show the Contact times for the Cathode Fig. 5(a) and Anode Fig. 5(b). The experimental conditions are defined in Table IV.

Figs. 6-8 are specific data plots from Experiment 2 of the arc root motion. They show the arc voltage, anode and cathode root movement in the upper figure, with images of the arc at given points in time identified in the upper figures. In Fig. 6, Trial T1, the arc is shown by consideration of the arc voltage 


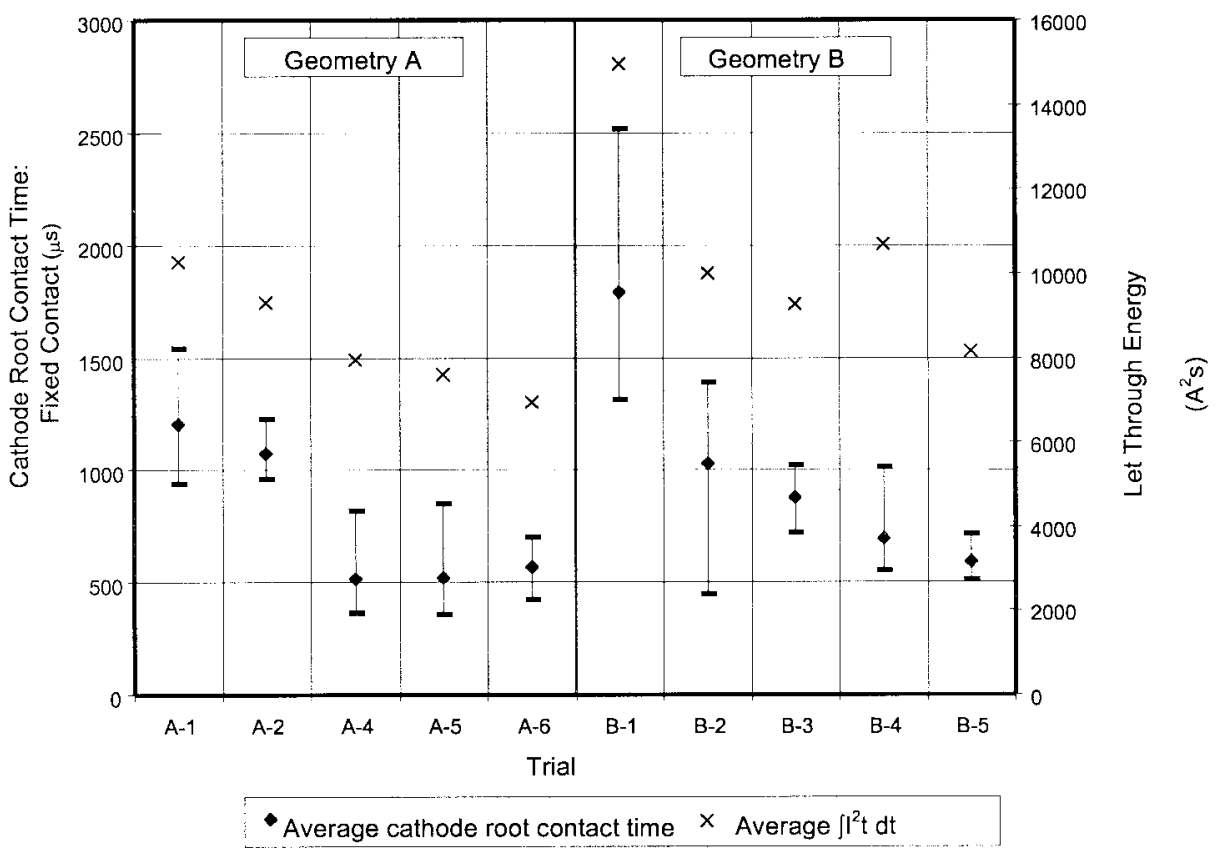

Fig. 4. Cathode root contact times on the fixed contact for Experiment 1, the arc contact time investigation; to be viewed with Table II. The let through energy is also presented.

characteristic, to ignite at $450 \mu \mathrm{s}$ after the current zero. With reference to the $Y$ displacement of the arc roots, the anode root (AR) motion starts at $650 \mu \mathrm{s}$, and the cathode root (CR) at $900 \mu \mathrm{s}$. These are not however the contact times used in the analysis, these are defined as follows.

1) The cathode root contact time $\left(t_{c}^{-}\right)$is measured relative to the time of arc ignition, in this case $450 \mu$ s after arc ignition. This is the time taken for the cathode root to move away from the first fiber position, this will include any delays due to the contact material and contact shape.

2) The anode root time $\left(t_{c}^{+}\right)$is also measured relative to the time of arc ignition, and is the time taken for the root position to reach $Y=10 \mathrm{~mm}$, in this case $800 \mu$ s after the start of the arc. This is the time taken for the arc root to move off the moving contact, and will include any delays at the point of arc ignition.

In Fig. 6 the arc position at $1150 \mu \mathrm{s}$ is shown in the arc image (1). The arc position is indicated by the white spot corresponding to the anode arc root on the moving contact, with the discharge shown to lie at an angle to the cathode arc runner. The cathode root is shown to have moved off the $\mathrm{Ag} / \mathrm{C}$ contact material. At (2) the anode root has moved off the moving contact. At (3) and (4) the anode and cathode arc root move toward the splitter plates.

In Fig. 7, for Trial T4, the arc is shown by consideration of the arc voltage characteristic to ignite at $450 \mu$ s after the current zero. The anode root is shown to start moving at 650 $\mu \mathrm{s}$, and the cathode root at $900 \mu \mathrm{s}$. The arc position at 1000 $\mu$ s is shown in the arc image (1), where the arc is shown on the moving contact, having moved off the $\mathrm{Ag} / \mathrm{C}$ contact material. The anode root then remains fixed for an extended period with a displacement of $4-5 \mathrm{~mm}$. This corresponds to a level arc voltage of 50-60 volts. At (2) the cathode root moves and is identified in arc image (2) by a second arc root appearing further down the fixed arc runner. At (3) the anode arc root moves off the moving contact allowing the cathode root to move.

In Fig. 8, for Trial T5, both arc roots are shown to move with a uniform velocity through the arc chamber, although the arc voltage plot shows a plateau level at approximately 60 Volts, between the positions shown in images (3) and (4).

\section{DISCUSSION}

\section{A. Experiment 1-Arc Contact Time Investigation}

In the following discussion the cathode root contact times referred to are the average $\left(t_{c}^{-}\right)$times for each trial in Fig. 4. For configuration A-1 and B-1 without steel backing strips, the average $\left(t_{c}^{-}\right)$time for geometry B is $1800 \mu$ s compared to 1200 $\mu$ s for geometry A. The addition of steel backing strips (A-2, B-2) leads to reduced times for both geometries, the reduction for arc chamber B is greater. The following observation can be drawn from the data:

1) For the moving contact velocity in arc chamber geometry A; replacing the linear contact mechanism (Trial A-2) with the high speed rotating mechanism (Trial A6) resulted in a decrease in the $t_{c}^{-}$time, from $1100 \mu \mathrm{s}$ to $600 \mu \mathrm{s}$.

2) For contact material in arc chamber geometry B; replacing the $\mathrm{Ag} / \mathrm{C}$ contact tips used in Trial B-1 with copper contact tips of the same step geometry, Trial B-3, led to a decrease in the $t_{c}^{-}$time, from $1300 \mu \mathrm{s}$ to $850 \mu \mathrm{s}$.

3) For contact tip geometry, using punched copper contacts, Trial B-4, instead of copper contacts with a step Trial B-3 led to a reduction in the $t_{c}^{-}$time, from $850 \mu$ s to $700 \mu \mathrm{s}$. 


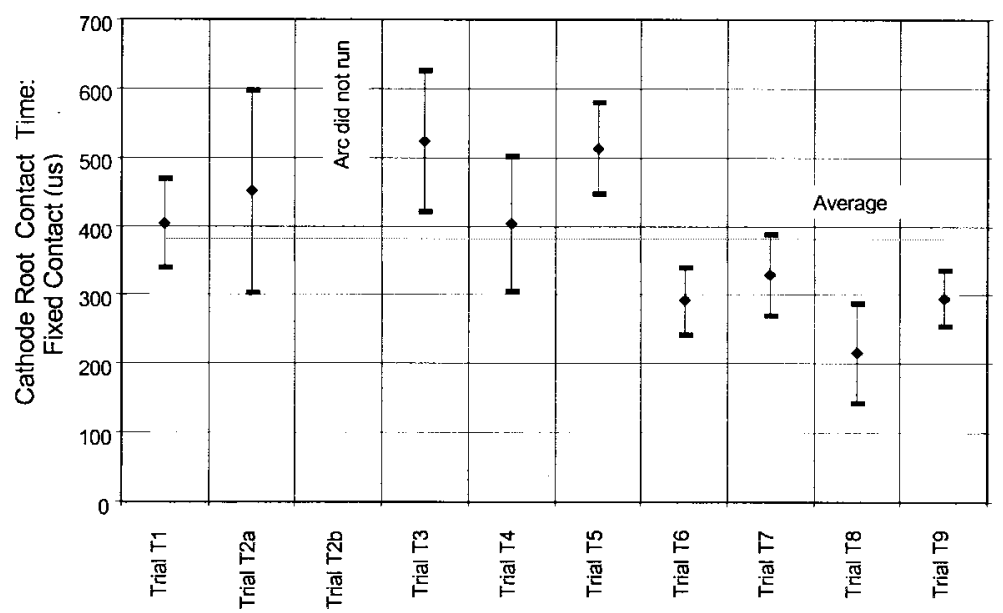

(a)

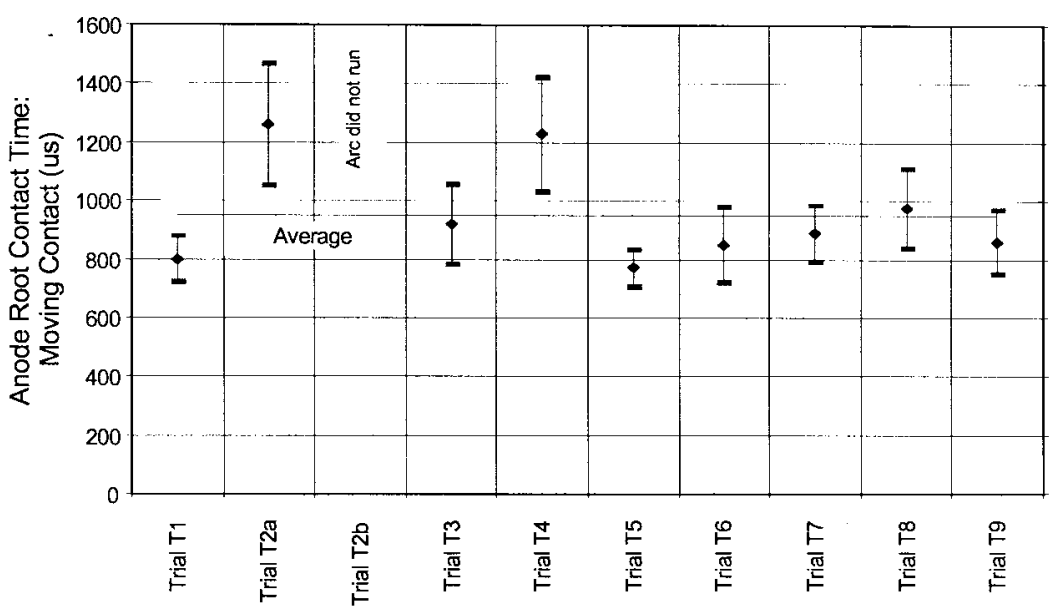

(b)

Fig. 5. (a) Cathode root contact times on the fixed contact for Experiment 2, the arc behavior analysis; to be viewed with Table IV. (b) Anode root contact times on the moving contact for Experiment 2, the arc behavior analysis; to be viewed with Table IV.

4) The addition of steel backing strips Trial B-5, to the contact configuration of Trial B-4 resulted in a further decrease in the $t_{c}^{-}$time, from $700 \mu$ s to $600 \mu \mathrm{s}$.

Using the average $t_{c}^{-}$time as an indicator of arc immobility these results confirm the general opinion that arc root immobility times are increased by the use of $\mathrm{Ag} / \mathrm{C}$ contact materials [13] and steps in the contact region [14], [15]. From a comparison of Trial B-1, B-3, and Trial B-4, the use of the $\mathrm{Ag} / \mathrm{C}$ contact material appears to have the dominant affect in reducing the cathode root motion. A comparison of the use of the $\mathrm{Cu}$ contact tip (B-3) and the punched tip (B-4) indicates that where there is no step there is a small improvement in performance. The particular combination of a bend in the runner in close proximity to the $\mathrm{Ag} / \mathrm{C}$ contact tip and the lack of a Fe backing strip creates the conditions for prolonged immobility.

The increased arc immobility times on $\mathrm{Ag} / \mathrm{C}$ contacts can be linked to the erosion characteristics of the material. $\mathrm{Ag} / \mathrm{C}$ contacts erode severely and the surface composition has been shown to change during the interruption of arcs over $1 \mathrm{kA}$.
The build up of carbon layers on the contact surface may contribute to the arc root immobility by leading to higher surface temperatures [16], causing the destruction of the oxide layers required for rapid arc root motion. Also, the ablated contact materials may condense on the arc runners adjacent to the contact, leading to a conductive layer on top of the oxide layer. The metal oxide layer emission necessary for rapid arc motion would not occur, as positive ions incident on the layers would be discharged by electrons supplied along the layer of condensed contact material. The presence of Carbon could also result in localized thermionic electron emission.

The use of steel backing strips behind the arc runners to increase the magnetic flux density in the arc chamber can reduce the immobility times, as can increasing the contact velocity. By encouraging early movement of the cathode root both the effects of heat damage to the oxide layers and carbon build up are avoided and arc root immobility times minimized.

In general the cathode root contact times in circuit breaker configuration (A) is either lower than or equal to that in geometry (B) for the same conditions, thus indicating an 

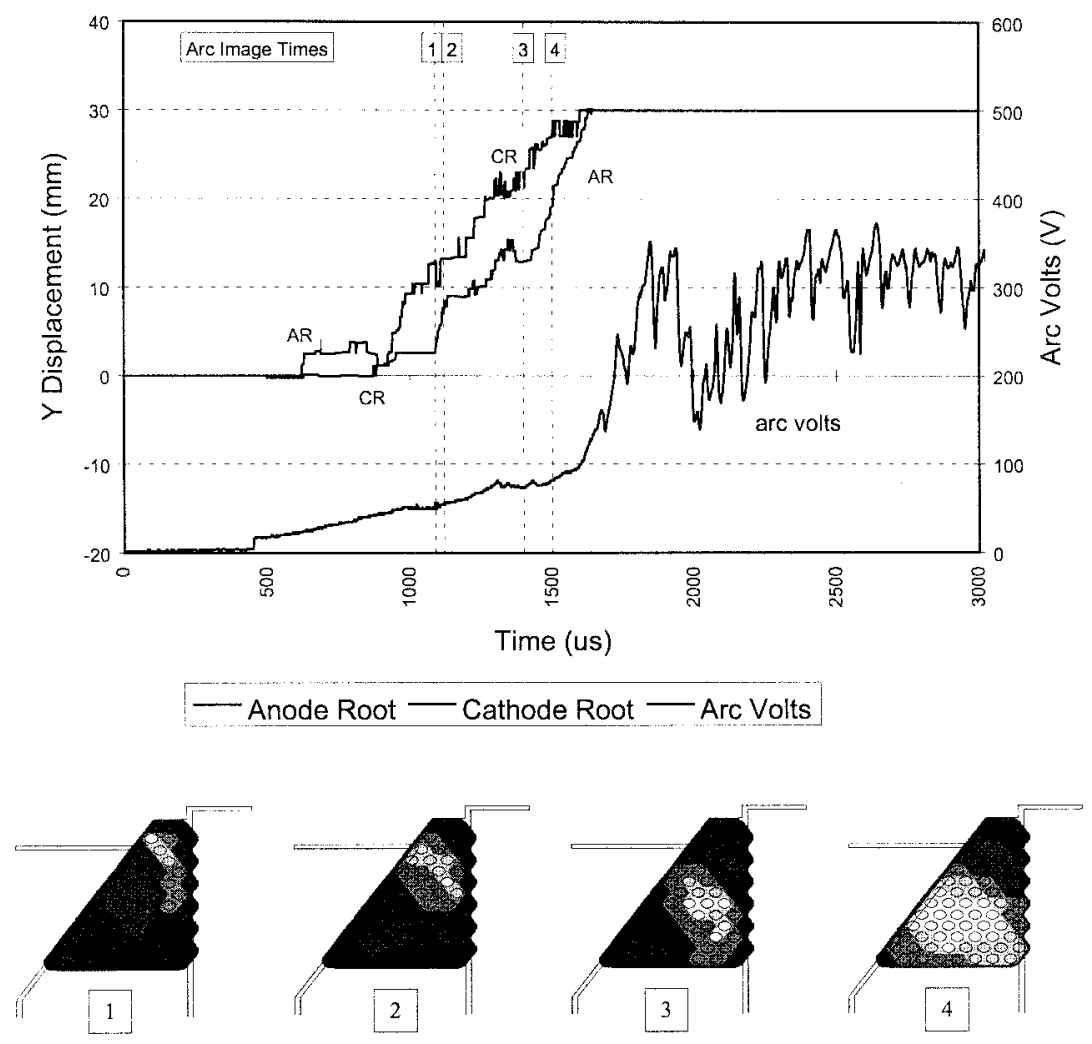

Fig. 6. Arc root trajectory, arc voltage, and selected arc images, for Trial T1.
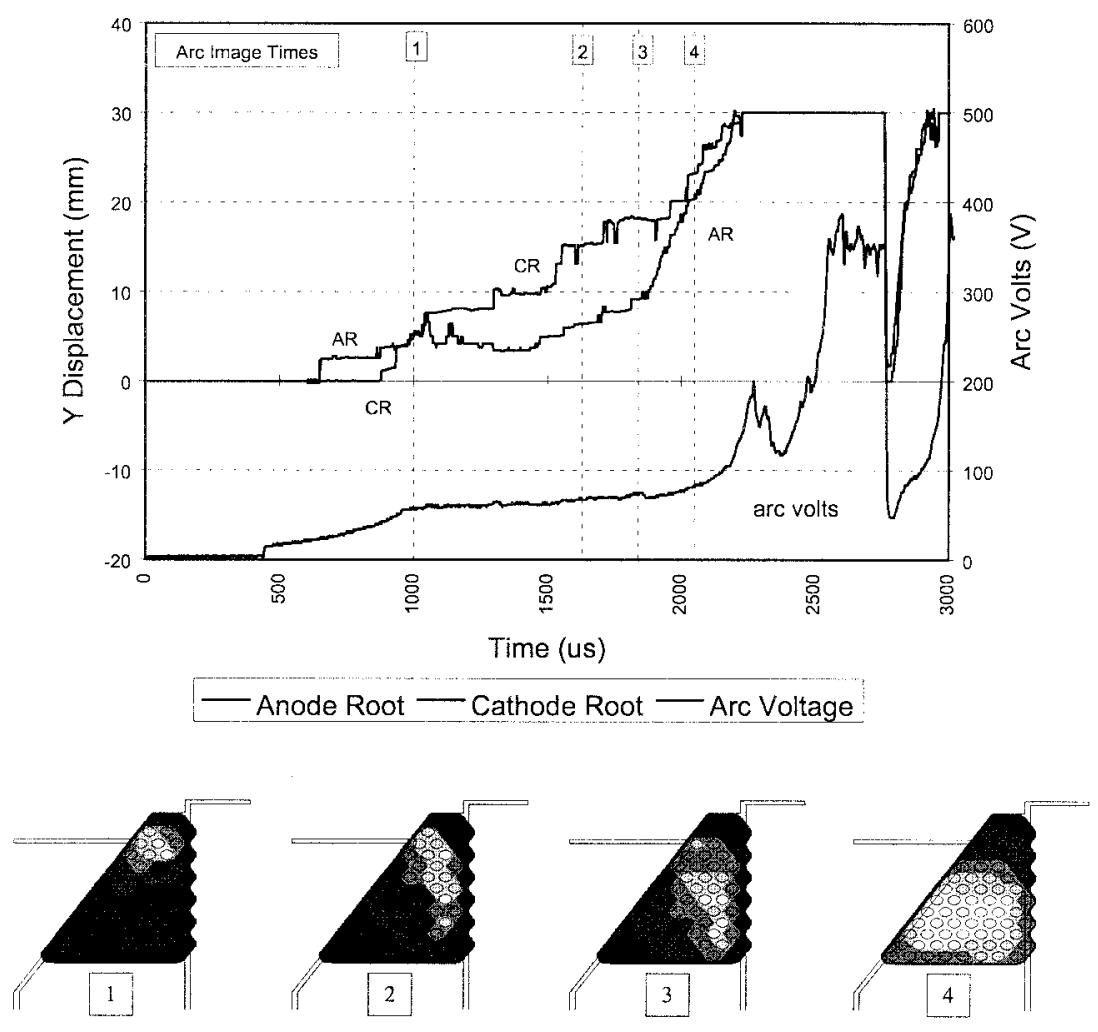

Fig. 7. Arc root trajectory, arc voltage, and selected arc images, for Trial T4. 

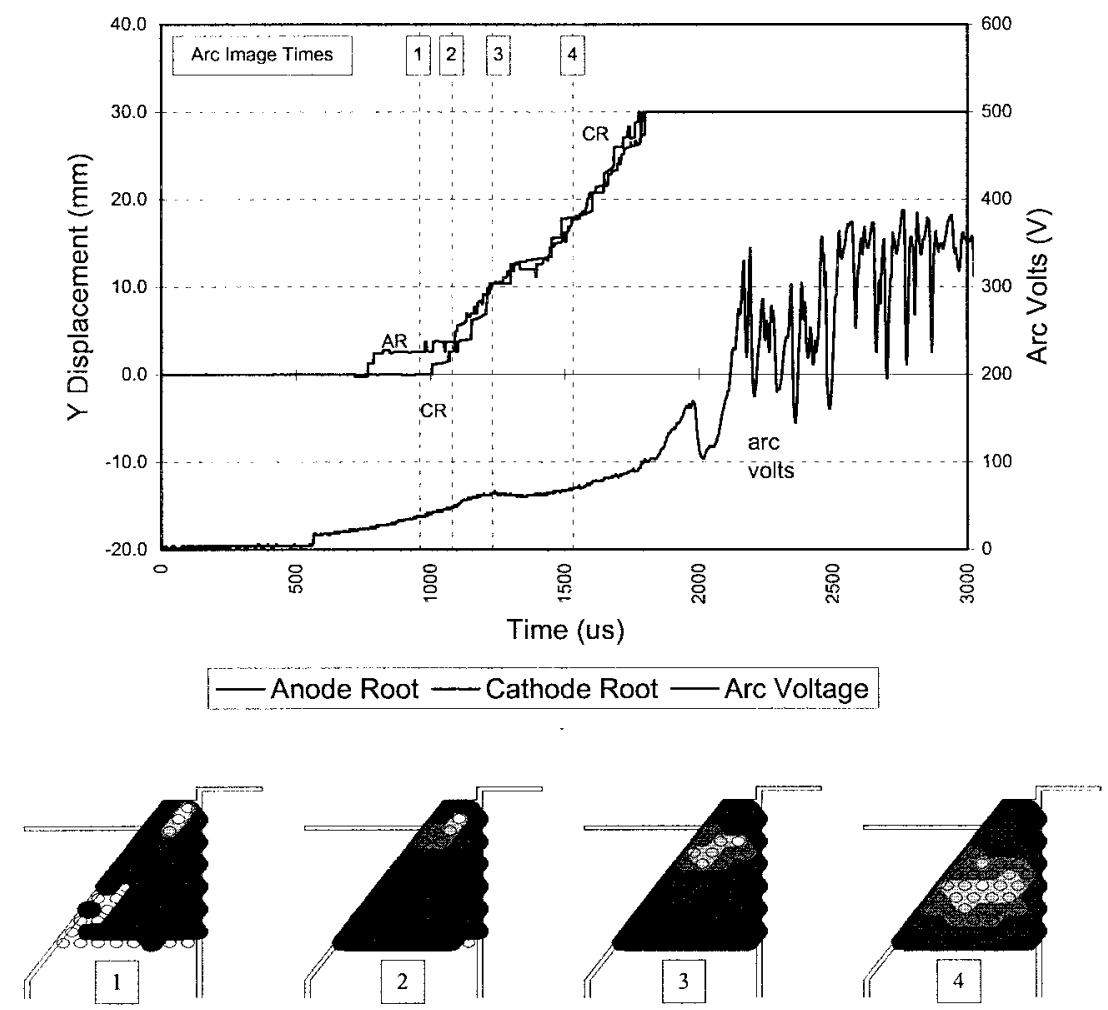

Fig. 8. Arc root trajectory, arc voltage, and selected arc images, for Trial T5.

improved circuit breaker performance for the former geometry. In all cases the let through energy is lower in geometry (A). The use of the second divergent runner in geometry (B) leads to a second point of cathode root immobility in the arc chamber, as the arc root sticks on the corner identified in Fig. 3, on the arc root motion. The effect of velocity presented by others as a key factor has been shown here to be important but not essential. The use of a high velocity does improve the performance of the device but often makes up for other areas of poor performance in terms of arc mobility. It has been shown here that with the use of a $\mathrm{Cu}$ contact without a step allows the device to show an improved performance at a lower velocity, compare (A-5 and A-6), Fig. 4. The use of the Ag/C material is essential to prevent contact welding.

\section{B. Experiment 2-Arc Behavior Investigation}

In this experiment detailed results were presented on both anode and cathode root motion in an arc chamber with contacts opening with a constant velocity. This allows observations to be drawn on the complex interrelationship between the two arc roots.

The cathode root is the source of electrons for the current through the arc column, and is generally considered to dominate the movement of the arc column. This may be the case when considering the motion of an arc moving continuously along plain parallel electrodes, but is not necessarily the case in more complex situations such as in a MCB. The cathode and anode root have been observed to move along plain surfaces and commutate across steps and gaps differently [15]. As the contact systems found in MCB's are rarely symmetrical it would be suprising if the anode root and cathode root moved away from the contact region together.

The anode root and cathode root motions are considered here for the data presented in Figs. 5(a) and (b). Consideration is also given to the case of trial T2. The levels selected for trial $\mathrm{T} 2$, were expected to produce long delays in the root motion, based on the observations made in Experiment 1, trial A-1. In the case of trial T2 the conditions for arc immobility are complemented with the use of a choked arc chamber and Acrylic sidewalls. The use of $\mathrm{Ag} / \mathrm{C}$ contact material with a step, coupled with no steel backing strip and an ablative material will lead to long delays. This has been shown to be the case and two modes of operation identified. For trial T2a the contact root times were extended whilst in trial $\mathrm{T} 2 \mathrm{~b}$ the arc failed to leave the contact region.

Anode Root Motion: The results presented in Fig. 5(a) and (b) show that the anode root contact time does not always follow the cathode root contact time. In trial T8 the cathode root contact time is low, whilst the anode root contact time is high. Conversely trial T5 has a high cathode root contact time and a low anode root contact time. This evidence shows that the movement of the anode root away from the contact region is not rigidly coupled to the cathode root.

Comparing the cathode root contact times in Fig. 5(a), for trial $\mathrm{T} 1$ and $\mathrm{T} 4$. In both cases the cathode root leaves the contact region after $400 \mu \mathrm{s}$. In Fig. 5(b) the anode root is delayed in trial T4 with an average time of $1200 \mu \mathrm{s}$, compared to $800 \mu \mathrm{s}$ in T1. The similarity of the cathode root times suggests that the improved performance to be expected with use of the flat contact surface is balanced 
by the delay associated with closing the vent and using acrylic in the chamber. It can be argued that the anode root events on the moving contact are not influenced by the fixed contact geometry, or with the runner configuration. The moving contact is in all cases $\mathrm{Ag}$ plated $\mathrm{Cu}$. In addition since the contact opening time is constant any delays associated with current commutation from the moving contact to the arc runner will be constant. It can be concluded that the anode root movement is impeded by closing the vent and by the use of acrylic in the arc chamber.

Comparing the arc root contact times for Trial T1 with those of Trial T5, Figs. 6 and 8. The cathode root contact times in T5 are higher whilst the anode root contact times are similar, $800 \mu \mathrm{s}$. In both cases the vent is open, but the material of the chamber has changed. This suggests that the anode root movement is affected by the venting process, and not by arc chamber material changes.

To confirm this observation in all cases with an open vent (T1, T5, and T9) the anode root times are between 800 and 860 $\mu$ s. In the cases with a closed vent (T3, T4, and T8) the anode root times are between 900 and $1200 \mu$ s. With a partially close vent (T2, T6, and T7), the anode times are between $850 \mu$ s (T6) and $900 \mu \mathrm{s}$ (T7), while T2a is $1260 \mu \mathrm{s}$. Trial T2 is a special case discussed above. The vent has an important influence on the ability of the anode root to transfer from the moving contact. With the vent closed or partially closed the pressure in the arc chamber ahead of the arc will be greater than the case with an open vent. The additional pressure will provide a force, which will act to prevent the anode root commutation across the gap between the moving contact and the runner. This appears to be more dominant on the anode because the anode root motion is not governed by emission processes.

Cathode Root Motion: The arc images show that the cathode root moves off the fixed contact pad and along the arc runner. The mechanism for forward cathode root motion requires an increased ion density forward of the cathode root [17]. This effect is disrupted by the failure of the anode root to commutate resulting in the arc column being angled backward, as seen in the images of Trials $\mathrm{T} 1$ and $\mathrm{T} 4$. A reduction in the cathode root velocity leads to the arc root interaction effect damaging the oxide layer, preventing high velocity motion with oxide layer type emission dominating. In addition, the arc column is not displaced forward of the cathode root so the arc is not likely to jump to a new arc root site forward of the cathode root, Fig. 9. As a consequence the cathode root is limited to low velocity with metal vapor type emission dominating.

For the cathode root motion to continue the anode root must commutate from the moving contact to the arc runner. The anode root commutation for Trial T4 occurs just after image 3, Fig. 7. The anode root can be seen to move at constant velocity after commutation from the arc root trajectory plot, Fig. 7. The cathode root velocity increases as the $Y$ displacement of anode root matches the cathode root. The two arc roots then move along the chamber together, image 4.

It is proposed that although the cathode root dominates arc motion along parallel arc runner, the anode root can exert a restraining influence on the cathode root in a MCB.

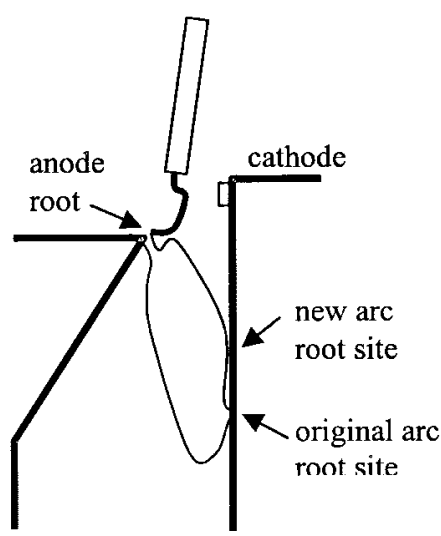

Fig. 9. Schematic diagram of arc in arc chamber geometry A. Based on data from optical fiber imaging system.

\section{CONCLUSION}

The results presented here provide an insight into the complex arc motion mechanisms occurring in miniature current limiting circuit breakers. The results were obtained under experimental conditions where opening contacts were considered in a flexible test apparatus. It has been demonstrated that the unique experimental methodology used, making use of the optical fiber imaging and analysis system, allows for a detailed and reliable study of arc motion between opening contacts. It has been shown that a high contact velocity is an important, but not essential parameter in providing arc root mobility.

The movement of both the arc roots should be considered when studying arc behavior in MCB's. A number of arc phenomena occur during the movement of the arc roots from the site of ignition to the arc stack. These include the movement of the roots from the initial ignition site, commutation from contacts to arc runners, and the subsequent movement of the arc roots along the runners. The results show that the anode root movement is not rigidly coupled to the cathode root movement. As the mechanisms that occur at the cathode root are different to those at the anode root the movement of the two roots are affected differently by changes in the experimental conditions.

The failure of the anode root to commutate from the moving contact prevents the arc column displacing forward of the cathode root. This interferes with the increased density of positive ions forward of the cathode root necessary for the cathode root to displace in the direction of the magnetic force, and hence interrupts the arc motion. The retardation of the cathode root movement by the anode will lead to the arc root interaction effect destroying the oxide layer. Metal vapor emission must therefore dominate, and the cathode root is limited to low velocity.

\section{REFERENCES}

[1] J. W. McBride, P. M. Weaver, and P. A. Jeffery, "Arc root mobility during contact opening at high current," IEEE Trans. Comp., Packag., Manufact. Technol. A, vol. 21, pp. 27-34, Mar. 1998.

[2] A. E. Guile, "Arc electrode phenomena," Proc. IEE, IEE Rev., vol. 118, pp. 1132-1155, Sept. 1971.

[3] A. E. Guile, T. J. Lewis, and P. E. Secker, "The motion of cold-cathode arcs in magnetic fields," Proc. IEE Part C 108, pp. 463-470, 1961. 
[4] J. G. J. Sloot and G. M. V. v. d. Bosch, "Some conditions for arc movement under the influence of a transverse magnetic field," Holectechniek, 2(1972)3, pp. 98-106.

[5] K. Poeffel, "Influence of the copper electrode surface on initial arc movement," IEEE Trans. Plasma Sci., vol. 4, pp. 443-448, Dec. 1980.

[6] W. Rieder, "Interaction between magnet-blast arcs and contacts," in Proc. 28th IEEE Holm Conf. Electrical Contacts, Sept. 13-15, 1982, pp. $3-10$.

[7] E. Gauster and W. Rieder, "Arc lengthening between divergent runners: Influence of arc current, geometry, and materials of runners and walls," in Proc. 42nd IEEE Holm Conf. Electrical Contacts, Chicago, IL, Sept. 16-20, 1996, pp. 1-10.

[8] P. M. Weaver and J. W. McBride, "High speed, medium resolution arc imaging in current limiting devices," in Proc. 17th Int. Conf. Electrical Contacts, July 1994.

[9] __ "Arc motion in current limiting circuit breakers," in Proc. 16th Int. Conf. Electrical Contacts, Sept. 92, pp. 285-288.

[10] "Magnetic and gas dynamic effects on arc motion in miniature circuit breakers," IEEE Trans. Comp., Packag., Manufact. Technol. A, vol. 17, pp. 39-45, Mar. 1994.

[11] R. Roy, A Primer on the Taguchi Method. New York: Van Nostrand Reinhold.

[12] P. A. Jeffery, J. W. McBride, J. Swingler, and P. M. Weaver, “An investigation into arc contact phenomena and current limiting performance of miniature circuit breakers using the Taguchi design of Experiments," in Proc. 19th Int. Conf. Electrical Contacts, Sept. 14-17, 1998.

[13] M. Lindmayer, "The influence of contact materials and chamber wall materials on the migration and the splitting of the arc in extinction chambers," IEEE Trans. Parts, Hybrids Packag., vol. PHP-9, pp. 45-49, Mar. 1973.

[14] W. Rieder, C. Veit, and E. Gauster, "Interaction of magnetically blown break arcs with insulating walls in the contact region of interrupters," IEEE Trans. Comp., Hybrids Manufact. Technol., vol. 15, pp. 1123-1137, Dec. 1992.

[15] W. Widmann, "Arc commutation across a step or a gap in one of two parallel copper electrodes," IEEE Trans. Comp., Hybrids Manufact. Technol., vol. CHMT-8, pp. 21-28, Mar. 1985.

[16] P. C. Wingert, "The effects of interrupting elevated currents on the erosion and structure of silver-graphite," in Proc. 42nd IEEE Holm Conf. Elect. Contacts, Chicago, IL, Sept. 16-20, 1996, pp. 60-69.

[17] P. E. Secker and A. E. Guile, "Arc movement in transverse magnetic fields at atmospheric pressure," Proc. IEE. Part A, vol. 106, pp. 311-320, 1959.

[18] G. R. Jones and M. T. C. Fang, "The physics of high-power arcs," Rep. Prog. Phys., vol. 43, pp. 1415-1465, 1980.

John W. McBride, for a photograph and biography, see this issue, p. 37.

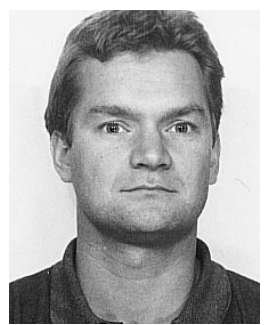

Peter A. Jeffery received the B.Eng. degree (with honors) from the Department of Mechanical Engineering, Southampton University, U.K., in 1993 and is currently pursuing the Ph.D. degree in short circuit arc motion in miniature circuit breakers.

$\mathrm{He}$ is research interests are in the properties of contact materials. 